\title{
Septik artrit cerrahisi ve izlemi
}

\author{
Septic arthritis surgery and follow up
}

\author{
Zekeriya Öztemür
}

Sivas Cumhuriyet Üniversitesi Tıp Fakültesi, Ortopedi ve Travmatoloji Anabilim Dalı, Sivas

\begin{abstract}
Septik artrit eklemlerin direkt ya da hematojen yol ile bulaşabilen bakteriyel enfeksiyonudur. Ciddi mortalite ve morbidite nedeni ile acil tanı ve tedavi gerektiren bir ortopedik acildir. Kesin tanının bir an önce konularak uygun tedavinin verilmesi önemlidir. Tedavi de eklemin artroskopik ya da açık irrigasyonu, iğne ile tekrarlayan irrigasyonlar ve parenteral antibiyotik tedavisi ile mümkündür. Cerrahi tedavinin şekli cerrahın tecrübesine bağlı olarak değişebilir.
\end{abstract}

Anahtar sözcükler: septik artrit; ortopedik enfeksiyon; eklem enfeksiyonu
Septic arthritis is a bacterial infection of the joints that transmitted directly or hematogenously. It is an orthopedic emergency requiring urgent diagnosis and treatment due to serious mortality and morbidity. It is important to make a definitive diagnosis as soon as possible and to give appropriate treatment. Treatment is also possible with arthroscopic or open irrigation of the joint, repeated irrigation with the needle and parenteral antibiotic therapy. The way of surgical treatment can vary depending on the surgeon's experience.

Key words: septic artritis; orthopedic infection; joint infection eptik artrit eklemlerin direkt ya da hematojen yol ile bulaşabilen bakteriyel enfeksiyonudur. ${ }^{[1,2]}$ Ciddi mortalite ve morbidite nedeni ile acil tanı ve tedavi gerektirir. Eklemlerinde şiddetli ağrı ve ısı artışı ile gelen bir hastada septik artritin yanı sıra, dejeneratif eklem hastalıkları, kristalin nefropatileri, reaktif artrit ve enflamatuvar artritler gibi pek çok enfeksiyöz dışı durumun da değerlendirilmesi gerekir. Kesin tanının bir an önce konularak uygun tedavinin verilmesi önemlidir.

Septik artrit insidansı normal popülasyonda 100.000 'de $2-10$ arasında bildirilmiştir. Eklem protezi öyküsü, romatoit artrit (RA), sistemik lupus eritematozis, kristal artropatisi, diyabet ve immunosupresif ilaç kullanımının septik artrit riskini artırdığı belirtilmiştir. ${ }^{[1,3]}$ Staphylococcus aureus septik artritten sorumlu en önemli etkendir. Bunun dışında diğer gram pozitif koklar ve özellikle streptococcal species etken olabilir. ${ }^{[1]}$ Prematüre, yenidoğan, ilaç bağımlıları, uzun süre hastane ve yoğun bakımda yatan hastalarda atipik bakteriyel etkenler ve mantar enfeksiyonları da dikkate alınmalıdır. ${ }^{[1,4]}$
Özellikle 18 aydan küçük çocuklarda, fizis matürasyonunun tam olmaması nedeni ile, metafiziyel dolaşımın epifiziyel dolaşıma doğru ilerlemesi septik artrit ile birlikte eş zamanlı osteomiyelit de görülebilmektedir. ${ }^{[5]}$

\section{PATOFIZYOLOJi}

Akut septik artritin oluşumundaki en önemli mekanizmalar sırası ile hemotojen yayılım, direkt yayılım (yakın dokulardaki enfeksiyonlar) ve iyatrojenik bulaştır. ${ }^{[4-6]}$ Akut septik artrit olgularındaki en sık mekanizma hematojen yayılımdır. ${ }^{[7]}$ Direkt bulaş genellikle travmalar ya da iyatrojenik olarak bakterilerin ekleme penetre olmasından kaynaklanır. Artroskopiden sonra $\% 0,14$, artrosentezden sonra $\% 0,037$ ve ön çapraz bağ rekonstrüksiyonundan sonra ise $\% 0,14$ oranında akut septik artrit riskinin olduğu belirtilmiştir. ${ }^{[8]}$

Bakteriler ekleme girdiğinde, sinoviyum çevresi bakteriler için ideal bir kültür ortamı olarak görev yapar. Sinoviyal membranların enfeksiyonun sonucu bağışıklık hücrelerinin ortama takviyesi gerçekleşir. Bu da eklemde kızarıklık, şişme ve ağıı oluşturur. Bağışıklık

- İletişim adresi: Prof. Dr. Zekeriya Öztemür, Sivas Cumhuriyet Üniversitesi Tıp Fakültesi, Ortopedi ve Travmatoloji Anabilim Dalı, Sivas Tel: 0505 - 2394436 e-posta: oztemurz@gmail.com

- Geliş tarihi: 27 Mayıs $2020 \quad$ Kabul tarihi: 4 Temmuz 2020 
cevabı devam ettiğinde sinoviyal hücreler proteolitik enzimleri salgılamaya başlar. ${ }^{[9]}$ illk sekiz saat içinde kıkırdak hasarı oluşmaya başlar. Süreç ilerledikçe, proteoglikanlar beşinci günde, kollajen ise bulaştan dokuzuncu günde bozulur. ${ }^{[1,10]}$ Enfeksiyon sürdükçe eklem içi basınç artışı, sinoviyal membranlarda tromboz ve eklem kıkırdağının harabiyeti devam eder. ${ }^{[1,11]}$

\section{KLINIK}

Genellikle hastalar ilgili eklemde ağrı şişlik ve işlev kaybı ile başvururlar. Ateş de eşlik edebilir. Tanı klinik, laboratuvar bulguları ve hekimin tecrübesine dayanır. Muayenede genelde eklemde şişlik, ballotman, ISı artışı, aktif ve pasif hareketlerde şiddetli ağrı ve kısıtlılık olabilir. Hasta değerlendirilirken hastanın enflamatuvar hastalık öyküsü, dizinde tekrarlayan sinovit olup olmadığı, travma hikâyesi, aşııı kullanıma bağlı (over using) travmatik sinovit öyküsü ve çocuk hastalar için yakında boğaz ağrısı geçirip geçirmediği sorgulanmalıdır. Akut tonsilit hem bakteriyemiye ikincil septik artrite hem de akut romatizmal ateşe bağlı artrite (ARF) neden olabileceği ayırıcı tanıda değerlendirilmelidir.

Akut septik artritle ilgili pek çok risk faktörü bulunmaktadır. Bunlar Tablo 1'de belirtilmiştir. ${ }^{[2,12,13]}$ Ancak özellikle romatoid artritli (RA) hastalarda genel

Tablo 1. Septik artrit risk faktörleri ${ }^{[2,12,13]}$

$\checkmark$ Altmış yaşüstü
$\checkmark$ Yakın zamanda bakteriyemi
$\checkmark$ Travma ya da cerrahi (eklem protezlerini de içeren)
$\checkmark$ Kortikosteroid enjeksiyonu
$\checkmark$ Romatoid artrit
$\checkmark$ Diyabet
$\checkmark$ Malignite (son 6-12 ayda alınan kemoterapi ya da
immunosupresif)
$\checkmark$ Azalmış bağışıklık (anti-tümör nekroz faktör tedavisi)
$\checkmark$ Siroz
$\checkmark$ Renal hastalık
$\checkmark$ Madde-ilaç bağımlıı̆ı (drug abuse)
$\checkmark$ Alkol bağımlıı̆ı̆ı
$\checkmark$ Kronik prostatit
$\checkmark$ Uzun süreli kortikosteroid tedavisi (astım, kronik obstrüktif
akciğer hastalığı, mevsimsel alerji)
$\checkmark$ Metil prednizolon alınmasını gerektiren inatçı sinüzit
$\checkmark$ Yakınlardaki dişle ilgili işlemler
$\checkmark$ Yakınlarda dövme yapılması
$\checkmark$ Genital travma

popülasyona göre septik artrit riski 4-15 kat daha yüksek olduğu bildirilmiştir. RA'da, eşlik eden şişlik ve ağrı hastalığın kendi özelliği olabilir ancak, hastaya verilen eklem içi kortikosteroid uygulanması da nadir olarak septik artrite neden olabilir. Literatürde bu oran 1:3.000 ile 1:50.000 arasında olabileceği bildirilmiştir. ${ }^{[6]}$ RA hastalara verilen kortikosteridlerin hastanın immunosupresif ilaçlar alması nedeni ile septik artrit açısından normal bireylere göre daha yüksek olduğu bildirilmiştir. ${ }^{[14]}$

Gut, psödogut, RA, travmatik sinovit, reaktif artrit gibi pek çok durum septik artrite benzer klinikle karşımıza çıkabilmektedir. Hastanın değerlendirilmesinde ayrıntılı bir öykü, özenli bir fizik muayene yapmak gerekir. Eklemde şişlik (ballotman), ısı artışı ile eklemin aktif ve pasif haraketlerinde ağrı ve kısıtlııłk görülebilir.

Ayırıcı tanı açısından hastanın ön-arka ve lateral direkt grafilerinin çekilmesi gerekir. Direkt grafilerde erken dönemde eklem aralığında genişleme ve yumuşak dokuda şişlik dışında fazla bulgu görülemeyebilir. Bazen yan grafilerde hava sıvı seviyeleri ve gaz gölgeleri bulunabilir. Direkt grafi özellikleri özgün olmasa da eklem aralığında darlık, osteofitlerin bulunması, artrit bulguları ya da simetrik darlık olması gibi osteoartroz ya da RA bulguları tanıda yardımcı olabilir. Geç dönem septik artritte juksta-artiküler osteoporoz, erozyon, eklem aralığında daralma, kortikal harabiyet gibi geç bulgular olabilir. ${ }^{[15]}$

Ultrasonografi, bilgisayarlı tomografi, manyetik rezonans (MR) görüntüleme, eklemlerdeki effüzyonu belirlemede kesin sonuç verebilir ancak effüzyonun septik artrite bağlı olup olmadığını teyit etme ya da dışlamaya yardımcı olamaz. ${ }^{[16]}$

Serum tam kan sayımı, Eritrosit sedimentasyon hızı (ESR) ve C-reaktif protein (CRP) seviyeleri septik artrit düşünülen hastalarda mutlaka çalışılmalıdır. Li ve ark., geriye dönük çalışmalarında septik artrit tanısında, periferik kanda beyaz kürenin 11.000 üzerinde olmasının $\% 48$, eklem sıvısında beyaz kürenin 50.000 üzerinde olmasının \%64 ve ESR'nin 30 mm/saat üzerinde olmasının \%96 duyarlı olduğunu bildirmiştir. ${ }^{[17]}$

Septik artrit tanısını doğrulamada eklem aspirasyonu önemlidir. Eklem aspirasyonu ayrıca hemartroz, gut, psödogut ve diğer enflamatuvar patolojilerin de ayırıcı tanısında yararlı olabilir. Tablo 2'de monoartiküler artritlerde eklem sıvısı bulguları gösterilmiştir. ${ }^{[17-19]}$ Eklem aspirasyonu yapılırken yanlış pozitif sonuçtan kaçınmak için cildin antiseptik solüsyonlar ile çok iyi temizlenmelidir ve kalın bir enjektör iğnesi veya intraket kullanılmalıdır. Aspirasyon sıvısının rengi, berraklığı ve viskozitesi gibi özellikler ön bir bilgi verebilir. Günlük pratiğimizde aspirasyon 
Tablo 2. Monoartiküler artritlerde eklem sıvısı bulguları ${ }^{[17-19]}$

\begin{tabular}{lllllc}
\hline Eklem sıvısı ölçümü & Normal eklem sıvısı & Non-enflamatuvar & Hemorajik & Enflamatuvar & Septik \\
\hline Renk & Açık & Sarı & Kırmızı & Sarı & Sarı-yeşil \\
Berraklık & Şeffaf & Şeffaf & Kanlı & Translusen-opak & Opak \\
Viskozite & Yüksek & Yüksek & Değişken & Düşük & Değişken \\
Beyaz küre & $2<109 /$ L & $2<109 /$ L & $2<109 /$ L & $2-100 \times 109 /$ L & $1-100 \times 109 /$ L \\
PMNL oranı & $<\% 25$ & $<\% 25$ & $\% 50-75$ & $<\% 50$ & $>\% 75-80$ \\
Kültür sonucu & Negatif & Negatif & Negatif & Negatif & Sıklıkla pozitif
\end{tabular}

yaparken mutlak surette sarı enjektör iğnesi veya gri intraket gibi kalın iğneleri tercih etmekteyiz. Şekil 1 a'da direkt mikroskopisi ve kültürü negatif reaktif artrit düşünülen bir hastanın eklem sıvısı, Şekil 1b'de ise ihmal edilmiş omuz septik artritine ait ameliyat içi eklem aspirasyon örneği görülmektedir. Her iki sıvının görünümleri arasında bariz fark olmasına karşın günlük pratikte mutlak surette alınan her eklem sıvısı aspirasyon örneğinin direkt mikroskopi ve kültüre gönderilmesi gerekmektedir. Eklem sıvısı aspirasyonu dışında glukoz, protein, laktat ve kristallerin incelenmesi de tanıya yardımcı olabilir. ${ }^{[16,18]}$

\section{TEDAVi}

Klasik olarak intravenöz antibiyotikler ile 4-6 hafta tedavi edilmesi tavsiye edilmektedir. Ancak bazı yeni çaIışmalarda daha az süre antibiyotik kullanımının hemen hemen aynı etkiyi göstermesine karşın daha düşük yan etkilerle karşılaşıldığını bildirilmektedir. ${ }^{[16,20,21]}$ Bir ileriye dönük çalışmada beşinci gün oral antibiyotiklere geçilebileceği belirtilmektedir. ${ }^{[16,20]}$ Başka bir çalışma da CRP seviyeleri $2 \mathrm{mg} / \mathrm{dL}$ 'nin altına düştüğünde hastaların güvenli bir şekilde oral antibiyotiklere geçebileceğini savunmaktadır. ${ }^{[16,22,23]}$ Kendi klinik uygulamamız; hastalara
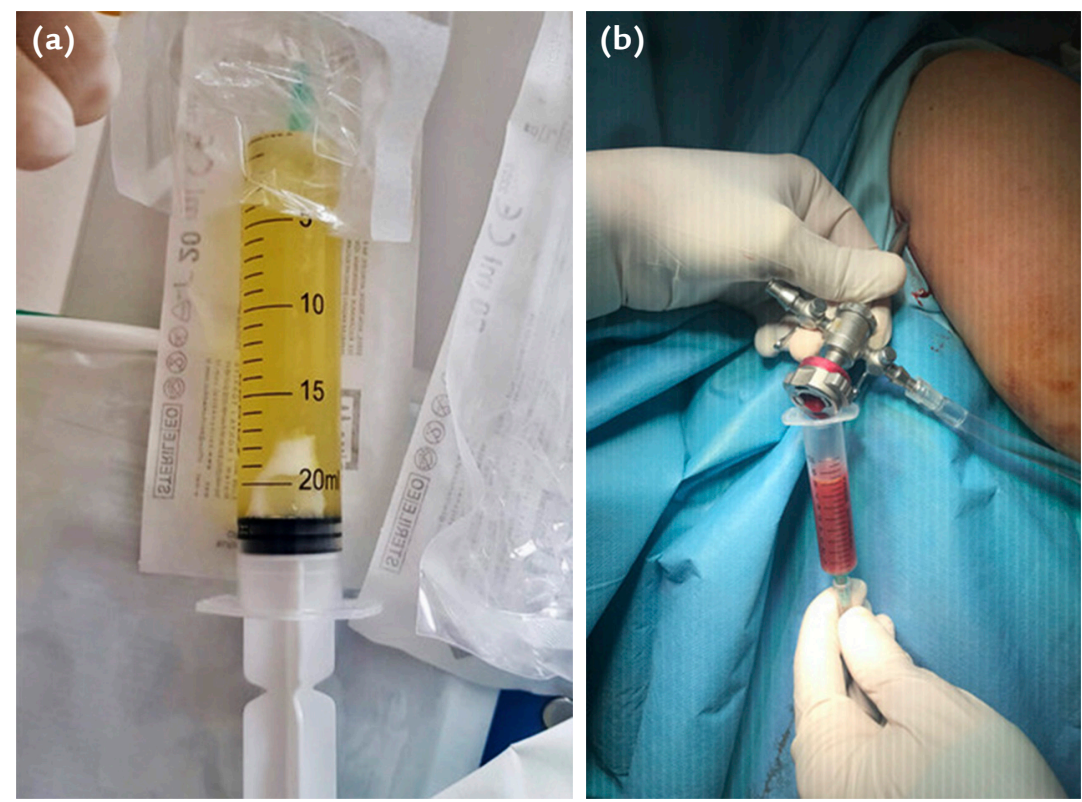

Şekil 1. a, b. Dizinde şişlik hafif ısı artışı olan, direkt mikroskop ve eklem kültürü negatif olan hastanın eklem sıvısının görünümü (a). Direkt mikroskop ve kültür de MRSA (-) S. aureus üreyen omuz septik artritinde artroskopi sırasında alınan eklem aspirasyon sıvısının görünümü (b). 
muhakkak direkt mikroskopi sonucuna göre enfeksiyon hastalıkları ya da pediatri uzmanlarının görüşleri de alınarak en az bir kaç hafta parenteral antibiyotik verilmesi şeklindedir. Kültür antibiyogram çıktıktan sonra gerekirse ilgili konsültanların fikirleri de alınarak antibiyotik düzenlenebilir. Hastanın kliniğinin düzelmesi ve akut faz reaktanlarında tatmin edici gerileme sağlanırsa oral antibiyotikler ile taburcu edilebilir. Takipte hastanın kliniği, haftalık ESR, CRP ve periferik kan beyaz küre takipleri ile yapılmaktadır. Ancak son yıllarda antibiyotiğe dirençli bakterilerin varlığı da göz önünde tutulmalıdır. Akut faz reaktanlarının ve klinik düzelmenin beklenenden yavaş olması durumunda dirençli mikroorganizmanın varlı̆̆ı ya da osteomiyelit akla gelmelidir.

Septik artrit cerrahi acil bir durumdur. Tedavide geç kalınması eklem harabiyeti, osteonekroz ve instabilite gibi komplikasyonlara yol açabilir. ${ }^{[1,24]}$ Tedavinin amacı eklemin basıncının azaltılması, yıkanması, bazı geç kalınmış olgularda ise sinovektomidir. ${ }^{[1,25,26]}$ Tedavi seçenekleri ise artrotomi, artroskopik yıkama ve ardışık iğne ile yıkama şeklindedir. ${ }^{[27-29]}$

Artroskopik teknik ve tecrübenin artması, işlemin minimal invaziv olması, daha iyi görüntüleme gerektiğinde sinovektomi yapılabilmesi gibi avantajları mevcuttur. Gächter Evre I ve Tip II olgularda artroskopik debridman tavsiye edilse de, Evre III olgularda da artroskopik yıkama ve sinovektomi yapılabilir. ${ }^{[1,25,28,29]}$ Evre IV olgularda ise kemik tutulumu mevcuttur ve bunlarda mutlaka artrotomi yapılması tavsiye edilmektedir (Tablo 3). ${ }^{[28,30]}$

Kendi klinik uygulamalarımızda artroskopik yıkama debridman ve gerekirse sinovektominin Gächter Evre I, II ve III septik artritte kullanıyoruz. Cerrahi mortalitenin yüksek olduğu hastalarda lokal anestezi altında artroskopik yıkama yada tekrarlayan iğne ile aspirasyon ve yıkama seçeneklerini kullanıyoruz.

Tablo 4'te septik artrit tanı ve tedavi algoritması gösterilmektedir. ${ }^{[1]}$

\section{KOMPLIKASYONLAR}

Septik artritin başlıca komplikasyonları eklem harabiyetinin yanı sıra osteomiyelit, bakteriyemi ve sepsistir. ${ }^{[16,31,32]}$ Eklem kıkırdağı harabiyetinin sonucu olarak büyüme bozukluğu, eklem çıkıkları, eklem hareketlerinde kısıtlılık ve erken eklem dejenerasyonları görülebilir. ${ }^{[16,33-37]}$ Komplikasyon oranı yenidoğanlarda ve tanının gecikmesi ile artar. ${ }^{[16,35]}$

\section{SONUÇ}

Septik artrit bir an önce tedavi edilmesi gereken ortopedik bir acildir. Tanısında hastanın klinik bulguları, radyografik tanı yöntemleri, ESR, CRP ve beyaz küre gibi pek çok tanı yöntemi olsa da eklem sıvısı bulgularının tanı değerinin çok yüksek olduğunu düşünüyoruz. Bazı olgularda klinik ve laboratuvar bulguları her zaman septik artriti tam olarak desteklemeyebilir. Bunlara rağmen hala septik artrit şüphemiz devam ediyor ise artroskopik bir girişim ile eklemin görüntülenmesi, eklem sıvısı ve sinoviyal doku örneklerinin alınmasını tavsiye etmekteyiz. Tedavide özelikle MRSA tipi bakterilere etkili bir antibiyotik seçilmelidir. Mutlak şekilde enfeksiyon hastalıkları ya da pediatri uzmanlarından destek alınmalıdır. Tedavi süresi hakkındaki klasik bilgilerimiz en az 4-6 hafta parenteral tedavi şeklinde olsa da hasta kliniğinin düzelmesi, ESR, CRP ve kan beyaz küre değerlerinin tatmin edici şekilde düşmesi durumunda tedavinin kalan kısımlarının oral tedavi ile yapılabileceğini düşünüyoruz. Hasta bazlı davranılmasının ve taburcu olduktan sonra hastanın klinik, ESR, CRP ve periferik kan beyaz küre açısından sıkı takibi gerektiği unutulmamalıdır. Cerrahi ve antibiyotik tedavisini rağmen klinik ve laboratuvar bulgularında istenen düzelmenin olmaması durumunda tanının tekrar gözden geçirilmesi, eşlik eden osteomiyelit olup olmadığının ve seçilen antibiyotiğin uygunluğunun değerlendirilmesi gerekmektedir.

Tablo 3. Diz septik artritinde Gächter sınıflaması ${ }^{[28,30]}$

\begin{tabular}{cll}
\hline Evre & Artroskopik bulgular & Radyografik bulgular \\
\hline I & Eklem sıvısında opasite ve sinoviyal mebranlarda kızarıklık & Radyografik değişiklik yok \\
II & Şiddetli enflamasyon, fibrinoz depozitler ve püy & Radyografik değişiklik yok \\
III & Sinoviyal membranlarda kalınlaşma, kompartman formasyonu & Radyografik değişiklik yok \\
IV & $\begin{array}{l}\text { Kıkırdağın infiltrasyonu ile birlikte agresif pannus, kıkırdağın } \\
\text { altının boşalması }\end{array}$ & $\begin{array}{l}\text { Subkondral osteoliz, muhtemel osseöz erozyonlar } \\
\text { ve kistler }\end{array}$
\end{tabular}


Tablo 4. Septik artrit tanı ve tedavi algoritması

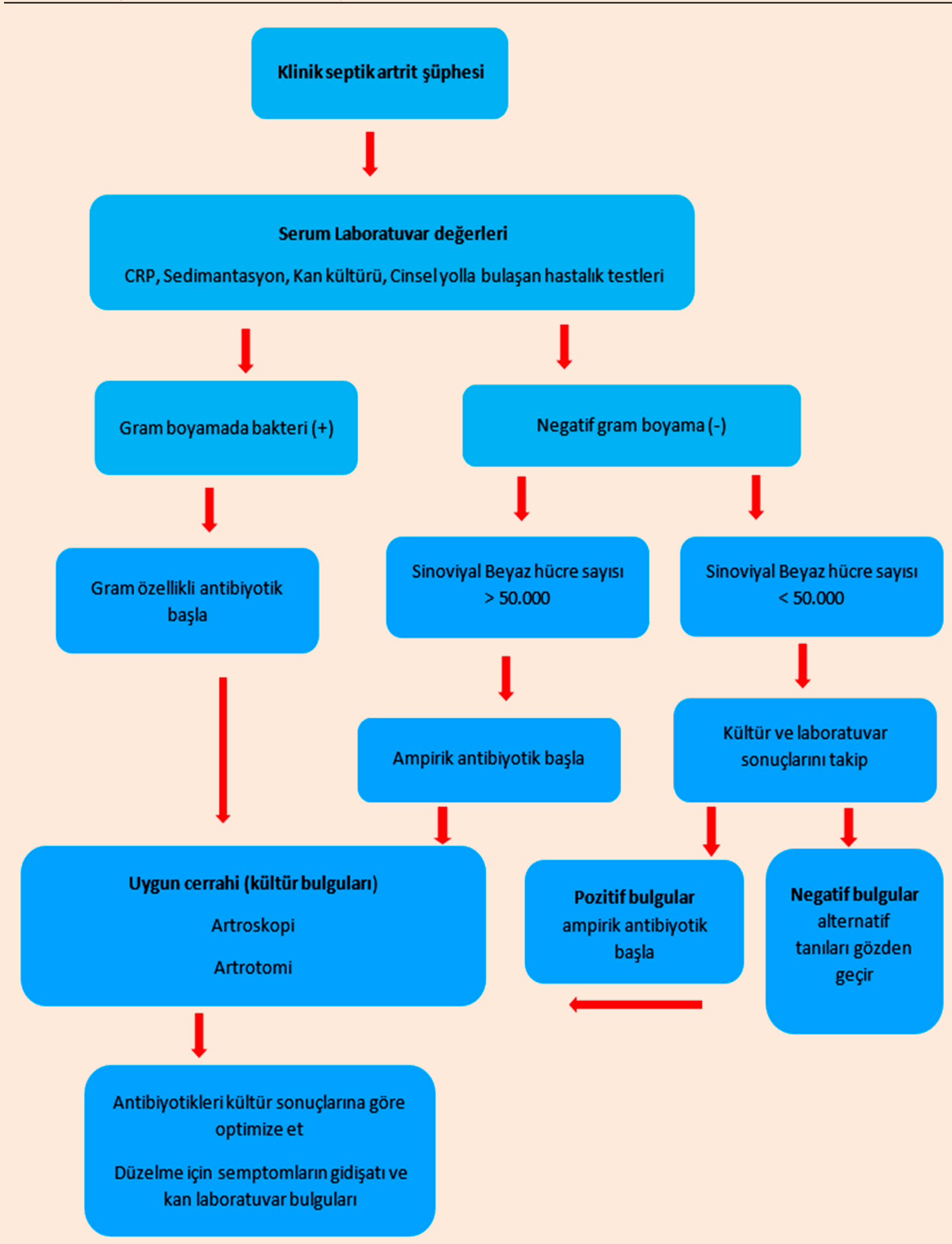




\section{KAYNAKLAR}

1. Elsissy JG, Liu JN, Wilton PJ, Nwachuku I, Gowd AK, Amin $\mathrm{NH}$. Bacterial Septic Arthritis of the Adult Native Knee Joint: A Review. JBJS Rev 2020;8(1):e0059. Crossref

2. Mathews CJ, Kingsley G, Field M, Jones A, Weston VC, Phillips M, Walker D, Coakley G. Management of septic arthritis: a systematic review. Ann Rheum Dis 2007;66(4):440-5. Crossref

3. Bouta EM, Bell RD, Rahimi H, Xing L, Wood RW, Bingham 3rd CO, Ritchlin CT, Schwarz EM. Targeting lymphatic function as a novel therapeutic intervention for rheumatoid arthritis. Nat Rev Rheumatol 2018;14(2):94-106. Crossref

4. Shirtliff ME, Mader JT. Acute septic arthritis. Clin Microbiol Rev 2002;15(4):527-44. Crossref

5. Sreenivas T, Nataraj AR, Menon J. Acute hematogenous septic arthritis of the knee in adults. Eur J Orthop Surg Traumatol 2013;23(7):803-7. Crossref

6. Sharff KA, Richards EP, Townes JM. Clinical management of septic arthritis. Curr Rheumatol Rep 2013;15(6):332. Crossref

7. Curtiss Jr PH. The pathophysiology of joint infections. Clin Orthop Relat Res 1973;(96):129-35. Crossref

8. Indelli PF, Dillingham M, Fanton G, Schurman DJ. Septic arthritis in postoperative anterior cruciate ligament reconstruction. Clin Orthop Relat Res 2002;(398):182-8. Crossref

9. Schneider P. Drug-induced lysosomal disorders in laboratory animals: new substances acting on lysosomes. Arch Toxicol 1992;66(1):23-33. Crossref

10. McCarthy JJ, Dormans JP, Kozin SH, Pizzutillo PD. Musculoskeletal infections in children: basic treatment principles and recent advancements. Instr Course Lect 2005;54:515-28.

11. Morrey BF, Bianco AJ, Rhodes KH. Suppurative arthritis of the hip in children. J Bone Joint Surg Am 1976;58(3):388-92. Crossref

12. Margaretten ME, Kohlwes J, Moore D, Bent S. Does this adult patient have septic arthritis? JAMA 2007;297(13):1478-88. Crossref

13. Hauschild O, Südkamp NP. Infektion des nichtprothetisch versorgten Gelenkes. Chirurg 2016;87(10):847-56. Crossref

14. Lee YK, Kim KC, Ha YC, Koo KH. Utilization of hyaluronate and incidence of septic Knee arthritis in adults: Results from the Korean national claim registry. Clin Orthop Surg 2015;7(3):318-22. Crossref

15. Weissman BN. Imaging of Arthritis and Metabolic Bone Disease. Imaging of Arthritis and Metabolic Bone Disease. Elsevier Inc.; 2009.

16. Gottlieb M, Holladay D, Rice M. Current Approach to the Evaluation and Management of Septic Arthritis. Pediatr Emerg Care 2019;35(7):509-13. Crossref

17. Li SF, Henderson J, Dickman E, Darzynkiewicz R. Laboratory Tests in Adults with Monoarticular Arthritis: Can They Rule Out a Septic Joint? Acad Emerg Med 2004;11(3):276-80. https://onlinelibrary.wiley.com/doi/ epdf/10.1111/j.1553-2712.2004.tb02209.x

18. Carpenter CR, Schuur JD, Everett WW, Pines JM. Evidencebased diagnostics: Adult septic arthritis. Acad Emerg Med 2011;18(8):781-96. Crossref

19. Goldenberg DL, Cohen AS. Acute infectious arthritis. A review of patients with nongonococcal joint infections (with emphasis on therapy and prognosis). Am J Med 1976;60(3):369-77. Crossref
20. Jagodzinski NA, Kanwar R, Graham K, Bache CE. Prospective evaluation of a shortened regimen of treatment for acute osteomyelitis and septic arthritis in children. J Pediatr Orthop 2009;29(5):518-25. Crossref

21. Peltola $H$, Pääkkönen $M$, Kallio P, Kallio MJT; OsteomyelitisSeptic Arthritis Study Group. Short-versus long-term antimicrobial treatment for acute hematogenous osteomyelitis of childhood: Prospective, randomized trial on 131 culturepositive cases. Pediatr Infect Dis J 2010;29(12):1123-8. Crossref

22. Arnold JC, Cannavino CR, Ross MK, Westley B, Miller TC, Riffenburgh RH, Bradley J. Acute bacterial osteoarticular infections: Eight-year analysis of $\mathrm{C}$-reactive protein for oral step-down therapy. Pediatrics 2012;130(4):e821-8. Crossref

23. Castellazzi L, Mantero M, Esposito S. Update on the management of pediatric acute osteomyelitis and septic arthritis. Int J Mol Sci 2016;17(6):855. Crossref

24. Hunter JG, Gross JM, Dahl JD, Amsdell SL, Gorczyca JT. Risk factors for failure of a single surgical debridement in adults with acute septic arthritis. J Bone Joint Surg Am 2015;97(7):558-64. Crossref

25. Aim F, Delambre J, Bauer T, Hardy P. Efficacy of arthroscopic treatment for resolving infection in septic arthritis of native joints. Orthop Traumatol Surg Res 2015;101(1):61-4. Crossref

26. Schröder JH, Krüger D, Perka C, Hufeland M. Arthroscopic Treatment for Primary Septic Arthritis of the Hip in Adults. Adv Orthop 2016;2016. Crossref

27. Stutz G, Kuster MS, Kleinstück F, Gächter A. Arthroscopic management of septic arthritis: Stages of infection and results. Knee Surg Sports Traumatol Arthrosc 2000;8(5):2704. Crossref

28. Böhler C, Dragana M, Puchner S, Windhager R, Holinka J. Treatment of septic arthritis of the knee: a comparison between arthroscopy and arthrotomy. Knee Surg Sports Traumatol Arthrosc 2016;24(10):3147-54. Crossref

29. Peres LR, Marchitto RO, Pereira GS, Yoshino FS, de Castro Fernandes $\mathrm{M}$, Matsumoto $\mathrm{MH}$. Arthrotomy versus arthroscopy in the treatment of septic arthritis of the knee in adults: a randomized clinical trial. Knee Surg Sports Traumatol Arthrosc 2016;24(10):3155-62. Crossref

30. Wirtz DC, Marth M, Miltner O, Schneider U, Zilkens KW. Septic arthritis of the knee in adults: Treatment by arthroscopy or arthrotomy. Int Orthop 2001;25(4):239-41. Crossref

31. Arvikar SL, Steere AC. Diagnosis and Treatment of Lyme Arthritis. Infect Dis Clin North Am 2015;29(2):269-80. Crossref

32. Dodwell ER. Osteomyelitis and septic arthritis in children: Current concepts. Curr Opin Pediatr 2013;25(1):58-63. Crossref

33. Hunka L, Said SE, MacKenzie DA, Rogala EJ, Cruess RL. Classification and surgical management of the severe sequelae of septic hips in children. Clin Orthop Relat Res 2020;(171):30-6. Crossref

34. Howard JB, Highgenboten CL, Nelson JD. Residual Effects of Septic Arthritis in Infancy and Childhood. JAMA 1976;236(8):932-5. Crossref

35. Abrishami S, Karami M, Karimi A, Soufali AP, Aslani HR, Badizadeh K. Greater trochanteric preserving hip arthroplasty in the treatment of infantile septic arthritis: Long-term results. J Child Orthop 2010;4(2):137-41. Crossref

36. Fabry G, Meire E. Septic arthritis of the hip in children: Poor results after late and inadequate treatment. J Pediatr Orthop 1983;3(4):461-6. Crossref

37. Cheng JCY, Lam TP. Femoral lengthening after type IVB septic arthritis of the hip in children. J Pediatr Orthop 1996;16(4):533-9. Crossref 